\title{
Cine drive-in como possibilidade de lazer artístico em período de pandemia COVID-
}

\section{9}

\author{
Cine drive-in as a possibility for artistic leisure during the COVID-19 pandemic period \\ Cine drive-in como posibilidad de ocio artístico durante el período pandémico del COVID-19
}

Recebido: 23/08/2021 | Revisado: 28/08/2021 | Aceito: 30/08/2021 | Publicado: 01/09/2021

\author{
Junior Vagner Pereira da Silva \\ ORCID: https://orcid.org/0000-0002-4098-9664 \\ Universidade Federal do Mato Grosso do Sul, Brasil \\ E-mail: jr_lazer@yahoo.com.br \\ Rogério Zaim-de-Melo \\ ORCID: http://orcid.org/0000-0002-0365-6000 \\ Universidade Federal do Mato Grosso do Sul, Brasil \\ E-mail: rogeriozmelo@gmail.com
}

\begin{abstract}
Resumo
O lazer tem como princípios básicos a disponibilidade de tempo e a liberdade do sujeito em optar por vivenciar algo. Portanto, a liberdade de escolha (atitude) faz-se fator fundamental. Entretanto, desde de março de 2020 a população brasileira enfrenta uma barreira nova, o SARS-COV2, um vírus altamente infeccioso, responsável pela disseminação da COVID-19. Mediante a ausência de vacina, o distanciamento social, proteção facial com máscara e higienização das mãos com álcool, foram (ou deveriam ter sido) as principais medidas de biossegurança, o que limitou várias atividades cotidianas ao contexto residencial. Ao reconhecer o lazer como elemento importante à vida e um direito social, a Universidade Federal de Mato Grosso do Sul (UFMS) formalizou parcerias e criou condições para oferta de experiências de interesse artístico do lazer através de projeção de filmes no formato drive in, de junho a dezembro de 2020, no AutoCine, equipamento específico do lazer que desde 1989 inoperante. O presente manuscrito, caracterizado como descrito e relato de experiência, objetiva apresentar e descrever o projeto "Autocine UFMS: reviver histórias, ressignificar espaços e experiências de lazer em tempos de pandemia".
\end{abstract}

Palavras-chave: Pandemia; Lazer; Biossegurança; Cinema.

\begin{abstract}
Leisure has as its basic principles the availability of time and the subject's freedom to choose to experience something. Therefore, freedom of choice (attitude) becomes a fundamental factor. However, since March 2020, the Brazilian population faces a new barrier, SARS-COV2, a highly infectious virus, responsible for the dissemination of COVID19. Due to the lack of vaccine, social distance, facial protection with a mask and hand hygiene with alcohol were (or should have been) the main biosecurity measures, which limited several daily activities to the residential context. By recognizing leisure as an important element to life and a social right, the Federal University of Mato Grosso do Sul (UFMS) formalized partnerships and created conditions to offer experiences of artistic interest in leisure through the projection of movies in the drive in format, from June to December 2020, at the AutoCine, specific leisure equipment that since 1989 has been inoperative. The present manuscript, characterized as described and experience report, aims to present and describe the project "Autocine UFMS: reliving stories, giving new meaning to leisure spaces and experiences in times of pandemic".
\end{abstract}

Keywords: Pandemic; Leisure; Biosafety; Movie theater.

\section{Resumen}

El ocio tiene como principios básicos la disponibilidad de tiempo y la libertad del sujeto para elegir experimentar algo. Por tanto, la libertad de elección (actitud) se convierte en un factor fundamental. Sin embargo, desde marzo de 2020, la población brasileña enfrenta una nueva barrera, el SARS-COV2, un virus altamente infeccioso, responsable de la diseminación del COVID-19. Debido a la falta de vacuna, la distancia social, la protección facial con mascarilla y la higiene de manos con alcohol fueron (o debieron ser) las principales medidas de bioseguridad, lo que limitó varias actividades diarias al contexto residencial. Al reconocer el ocio como un elemento importante para la vida y un derecho social, la Universidad Federal de Mato Grosso do Sul (UFMS) formalizó alianzas y creó condiciones para ofrecer experiencias de interés artístico en el ocio a través de la proyección de películas en formato drive in, a partir de junio. a diciembre de 2020, en el AutoCine, equipamiento de ocio específico que desde 1989 se encuentra inoperativo. El presente manuscrito, caracterizado como descrito y relato de experiencia, tiene como objetivo presentar y describir el proyecto "Autocine UFMS: revivir historias, dar un nuevo significado a los espacios de ocio y experiencias en tiempos de pandemia".

Palabras clave: Pandemia; Ocio; Bioseguridad; Cine. 


\section{Introdução}

A partir da revolução industrial, com a instituição do tempo social através do relógio, as ações cotidianas passaram a dispor de períodos específicos e fragmentados, dentre elas, o lazer, advento da sociedade moderna, influenciado por quatro acontecimentos históricos relacionados ao aspecto tempo (regulamentação da jornada de trabalho diário, descanso semanal remunerado, férias e aposentador) (Dumazedier, 1979).

Com a fragmentação do tempo social, a organização do cotidiano passa a ser demarcada hierarquicamente, com momentos programados e tempos estruturados para cada tipo de vivência. Ao longo de sua constituição, as instituições sociais atribuíram mais ou menos valor a uma ou a outra manifestação.

Colonizada pela epistemologia do Norte (Sousa Santos \& Meneses, 2010), sobretudo a partir da influência do francês Dumazedier (1979), a realidade brasileira demonstra-se ainda bastante demarcada por posições polares em relação ao lazer tempo das obrigações (trabalhistas, religiosas, familiares, escolares e sociais) x tempo do divertimento (lazer); dias da semana (usufruir o tempo disponível em casa com o descanso) x finais de semana (exaltação em festas); período de trabalho x período de férias.

No entanto, em meados de março de 2020, a exemplo do que vinha ocorrendo em outros países desde fevereiro (China, Itália, Espanha), a organização das atividades e tempo social, deparou-se a um quadro adverso e caótico, jamais vivenciado por esta geração, a pandemia COVID-19, decorrente do coronavírus.

Oriundos de reservatórios de animais, o coronavírus humano (HCoVS), desde 2002, se mostrou altamente patogênico e responsável pela Síndrome Respiratória Aguda Grave (SARS) (Paules, Marston, \& Fauci, 2020; Wit, et al., 2016). Apresentando características de um tipo de pneumonia atípica e nova, em dezembro de 2019, no município de Wuhan, China, um novo vírus foi identificado como SARS-COV2, responsável pela doença COVID-19 (Liu, et al., 2020; Rothan \& Byrareddy, 2020), resultando no contágio de 33.738 chineses e obtido de 811 (Liu, et al., 2020).

Com taxa média de transmissão de 3.28 (Liu, et al., 2020), o vírus proliferou-se rapidamente pela China, Europa e resto do mundo, sendo classificado pela Organização Mundial de Saúde (OMS) como pandemia mundial. Em nível mundial, até 12 de março, 125.048 pessoas haviam sido infectadas (Mehta, et al., 2020), chegando a 5.939 .234 milhões de infectados e 367.255 mil mortos (Who, 2020).

No Brasil, o primeiro caso de infecção foi identificado em 26 de fevereiro. Após retornar da Lombardia, norte da Itália, um morador de São Paulo com quadro sintomático (febril, tosse seca, dor de garganta e dor de cabeça), testou positivo (Cunha, et al., 2020). Em 30 de maio de 2020, no Brasil, haviam 498.440 mil casos de pessoas infectados e 28.834 mortos, com 5.8\% de letalidade (Ministério da Saúde, 2020).

Isto porque, a infecção ocorre por intermédio de gotículas respiratórias em aerossóis, de alto potencial de propagação e o quadro clínico dos infectados variam de assintomáticos a quadros graves, o que dificulta a identificação dos infectados. Desde seu surgimento, até julho de 2020, nenhum medicamento específico de prevenção, tratamento ou cura, foi cientificamente comprovado. Os mecanismos de defesa, no primeiro semestre de 2020, limitaram-se aos cuidados com a higiene, proteção facial com máscaras e, sobretudo, distanciamento social.

Frente aos riscos eminentes do vírus e o acelerado grau de contágio, medidas em nível estadual e municipal foram tomadas, como a implantação de normas de distanciamento social em diversos ramos de atividades, como as artísticas, que teve a suspensão das atividades em cinemas, museus, teatros, lonas, arenas e centros culturais - centros de artesanato, museus, bibliotecas, teatros, cinemas e demais equipamentos culturais (Estado do Rio Grande do Norte, 2020; Prefeitura Municipal do Rio de Janeiro, 2020). Tais medidas corroboraram com que o índice de distanciamento social atingisse o pico (62.2\%) em 20 de março (InLoco, 2020). 
Especificamente em Campo Grande, capital do Mato Grosso do Sul, em 15 de março de 2020 foi decretado pelo executivo municipal a proibição da realização de eventos em espaços artísticos (cinemas, museus, teatros, bibliotecas e centros culturais) com público superior a 100 pessoas (Prefeitura Municipal de Campo Grande, 2020).

Em que pese necessário, vez que diante do elevado índice de contágio, o distanciamento social mostrava ser o principal recurso preventivo, a medida trouxe impactos aos diferentes setores profissionais, dentre eles, o artístico, com efeitos negativas à economia, ocupação do mercado de trabalho, renda familiar e garantia do acesso a direitos sociais.

O meio artístico é uma importante atividade comercial e de ocupação profissional no Brasil. Em 2017, 325,4 mil organizações atuavam nesse ramo, empregando 1,9 milhão de pessoas, a maioria assalariadas $(76,1 \%)$, com rendimentos mensais médios de $\mathrm{R} \$ 3.530,00$ (três mil e quinhentos e trinta reais (Instituto Brasileiro de Geografia e Estatística, 2019). Entretanto, a proibição de funcionamento de espaços como teatros, cinemas, museus, centros culturais, dentre outros, afetou não apenas a economia, mas também impediu a efetivação do direito social ao lazer, vez que restritos ao espaço da moradia, a população não dispôs de políticas públicas culturais voltadas à democratização do acesso aos interesses artísticos do lazer.

O impacto negativo da pandemia ao lazer de brasileiros foi observado na população adulta, com impedimentos a frequentarem bares, shows, apresentações artísticas e esportivas e academias de ginástica/musculação (Silva, et al., 2020). A populações específicas, como universitários, ocorrem a diminuição com o envolvimento com o lazer de modo geral (Silva, 2021; Matos, Pinheiro, \& Bahia, 2020) e, de modo específico, com a prática de atividade física (Tavares, et al., 2020).

Ante ao quadro, propostas adaptadas para o período de pandemia e respeito ao distanciamento social foram criadas com uso de recursos tecnológicos, com circulação por meio de streaming, e-books virtuais e shows já existentes. Ainda, lives foram realizadas com shows musicais de artistas renomados que, mediante o potencial publicitário, mesmo que em escala inferior de arrecadação quando comparado ao período não pandêmico, conseguiram se manter ativos por meio de patrocínios, como os realizados por Gustavo Lima, Jorge e Mateus, Marília Mendonça, Bruno e Marrone, Pericles, Marcos e Belucci, Matheus \& Kauan, Michell Teló, Parangolé, Zé Neto e Cristiano, Alexandre Pires, Fernando e Sorocaba, Wesley Safadão, Ferrugem, Raça Negra, Ludmilla, Simone e Simaria, Luan Santana), dentre outros.

Embora importantes, viáveis e adequadas à realidade imposta pela COVID-19, o acesso as atividades artísticas limitaram-se aos conteúdos já produzidos e com possibilidade de veiculação via redes virtuais (televisores, tv por assinatura, computadores, tabletes, vídeos games, celulares e pacote de internet) e execução no ambiente doméstico.

A partir de tais evidências, a Coordenação de Cultura e Esporte da Universidade Federal de Mato Grosso do Sul (UFMS), repartição burocrática pertencente a administração pública, compreendendo que o Estado, por intermédio de seus aparatos burocrático-administrativo (Dye, 2010; Bobbio, 1987), figura como produtor por excelência de políticas públicas (Souza, 2006) e deve democratizar o acesso a experiências artísticas culturais a partir do processo duplamente educativo que orienta o lazer, avaliou a importância da criação de mecanismos que viabilizassem o acesso a atividades relacionadas ao conteúdo artístico de modo presencial, interesse do lazer que, segundo Silva e Sampaio (2011), se manifesta pelo contato com o estético, na busca por manifestações artísticas como imagem, dança, teatro.

Dentre o rol de atividades possíveis, elegeu-se aquela que dispõe de valor histórico e artístico, a contemplação de filmes dentro de veículos automotores por meio de uma ação de extensão, a qual teve por objetivo promover atividades artísticas durante a pandemia. Em específico, objetivou ofertar à comunidade campo-grandense a contemplação de filmes com a permanência dos usuários no interior de veículos e estabelecer parcerias para viabilizar o fomento de atividades culturas no âmbito institucional em período de pandemia, visando o atendimento da comunidade universitária e externa a ela.

Diante ao exposto, o presente manuscrito tem por objetivo apresentar e descrever o projeto "Autocine UFMS: reviver histórias, ressignificar espaços e experiências de lazer em tempos de pandemia". Especificamente, objetiva apresentar os resultados alcançados; percepção dos participantes e limitações evidenciadas. 


\section{Metodologia}

O manuscrito consiste em estudo descrito, do tipo relato de experiência, do tipo teórico-prático (Demo, 2012), referente ao Projeto de Extensão "AutoCine UFMS: reviver histórias, ressignificar espaços e experiências de lazer em tempos de pandemia".

O projeto em tela foi submetido ao Edital COVID-19 (Projetos e Ideias - PROPP/PROECE/AGINOVA/UFMS 22/2020), destinado a seleção de ideias e projetos de pesquisa, extensão e inovação para o enfrentamento do coronavírus e obteve aprovação como ação de extensão pelo edital nº 107/2020 - PROECE/PROPP/.

Posteriormente a sua aprovação, foi estabelecido acordo de cooperação juntamente com a Secretaria Municipal de Cultura e Turismo de Campo Grande/MS (SECTUR), de modo a realizarem o projeto, a qual competiu a responsabilidade por disponibilização de servidores do seu quadro para organização dos veículos e viabilizar junto a Vigilância Sanitária, servidores para procederam o atendimento de biossegurança no acesso ao AutoCine.

Ainda, contou com a parceria da Fundação Estadual de Cultura, responsável pelo financiamento da equipe técnica responsável pela projeção e sonorização. Por fim, contou com apoio do Serviço Social do Comércio, que disponibilizou filmes que os direitos autorais se encontravam sob sua gerência.

Adicionalmente, configura-se em pesquisa documental, que trabalha com materiais ainda não submetidos apreciação analítica (GIL, 2008, p. 51), sendo as publicações de jornais a respeito da percepção dos participantes o objeto da análise.

\section{Resultados e Discussão}

O cinema faz parte da vida humana desde o início do Século XX, quando os irmãos Lumiére, em Paris, exibiram pela primeira vez pequenos filmes. Deste início até os dias de hoje são milhares de filmes, os da indústria hollywoodiana, os orientais, os europeus, os indies e os brasileiros.

Com várias sociedades, incluindo a brasileira, o cinema passou a ser, desde as primeiras décadas do século XX, uma das formas culturais mais significativas. Surgindo como modalidade moderna de lazer, rapidamente conquistou adeptos, provocando novas práticas e novos ritos urbanos. Em pouco tempo, o cinema transformou-se numa instância formativa poderosa, na qual representações de gêneros, sexuais, étnicas e de classe eram (e são) reiteradas, legitimadas e marginalizadas (Louro, 2000, p. 424)

Porém, a exibição de filmes não ficou restrita a salas de cinema, vez que o norte-americano, Richard Hollingshead, diante do desconforto de sua mãe nas poltronas das salas, buscou uma solução que fosse ao mesmo tempo confortável e que permitisse assisti-lo de forma diferente ao tradicional. Fazendo experiências em sua residência, de modo a simular a tela, amarrou um lençol entre duas árvores e estacionou seu carro em frente, estando o veículo equipado com um projetor de filmes acima. Nascia o cine drive-in ou autocine. No Brasil, o cine drive-in chegou em 1968 (Fernandes, 2020) e, no Mato Grosso do Sul, em 1972.

Neste contexto, nasceu o AutoCine UFMS, que construído em 1972, dispõe de tela de 600 polegadas $(7 \mathrm{~m} 47 \mathrm{~cm}$ de altura e $13 \mathrm{~m} 28 \mathrm{~cm}$ de largura) e capacidade para receber 128 carros. Seu funcionamento foi gerenciado por uma empresa privada, com acesso via cobrança de bilheteria e os recursos obtidos e destinados à universidade, aplicados na compra de livros para biblioteca da instituição. Seu funcionamento foi mantido até 1989, quando desativado.

Sua reativação ocorreu em 2020, com pequenas ações de manutenção, especificamente para o projeto em relato. Em decorrência da necessidade do distanciamento social em período de pandemia, o acesso foi limitado a 70 veículos, sendo os espaços ocupados alternadamente - vaga sim, vaga não. 
Research, Society and Development, v. 10, n. 11, e300101119727, 2021

(CC BY 4.0) | ISSN 2525-3409 | DOI: http://dx.doi.org/10.33448/rsd-v10i11.19727

Figura 1. Vista aérea do AutoCine UFMS.

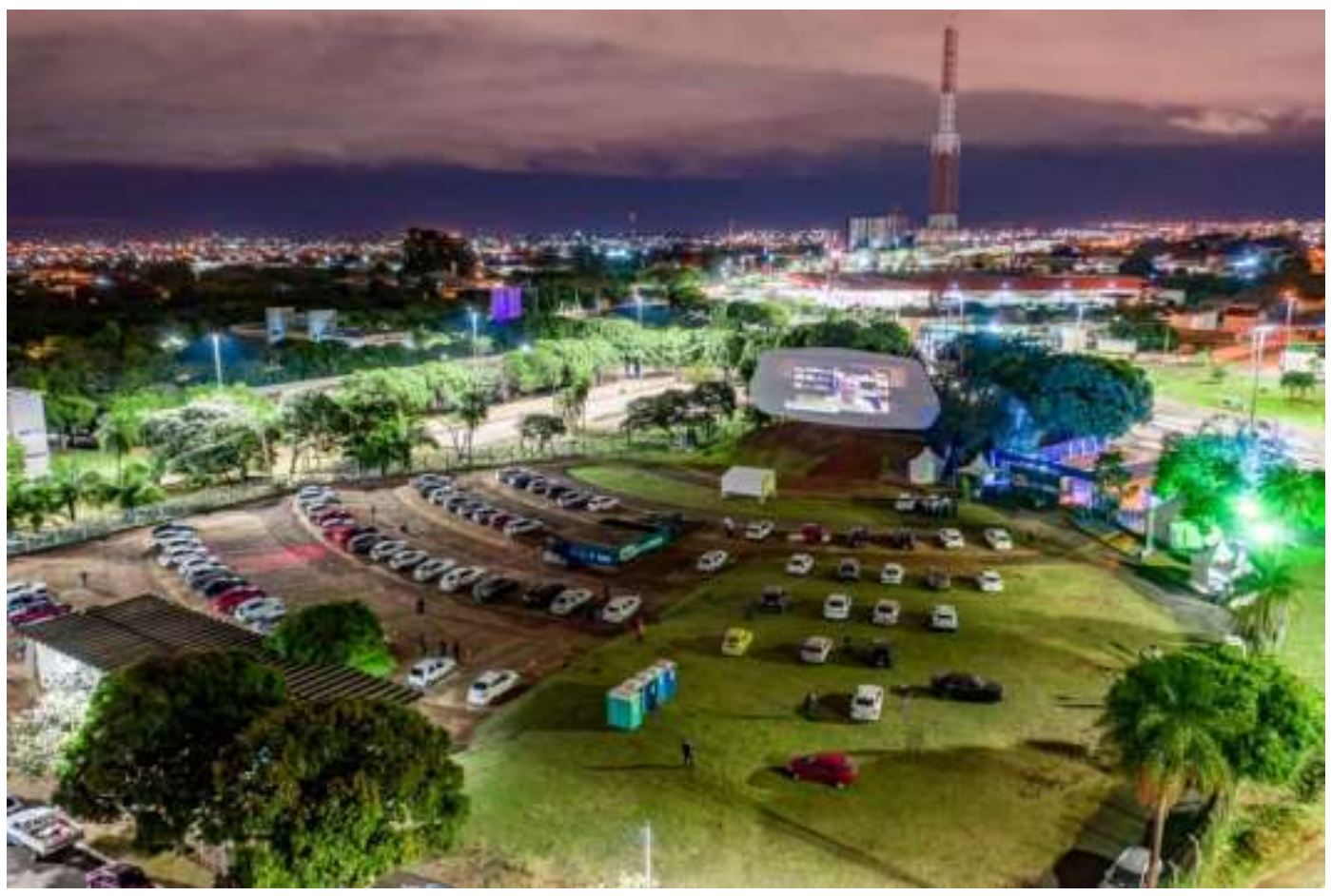

Fonte: Cyro Clemente/Ovo Filmes.

$\mathrm{Na}$ execução do projeto foram disponibilizados banheiros químicos e uma cantina adaptada para comercialização de alimentos aos participantes. O acesso aos alimentos era dado por intermédio do acionamento da pisca alerta dos veículos, ocasião em que os vendedores se deslocavam até os veículos. 
Quadro 1. Filmes projetados no projeto "AutoCine UFMS: reviver histórias, ressignificar espaços e experiências de lazer em tempos de pandemia”.

\begin{tabular}{|c|c|c|c|c|c|c|}
\hline Data & Filme & Lançamento & Sessões & Gênero & Produtora & Distribuição \\
\hline $28 / 6$ & Eu e meu guarda-chuvas & 2010 & 2 & Aventura e fantasia & Conspiração filmes & Fox Film do Brasil \\
\hline $5 / 7$ & O Grilo Feliz e os Insetos Gigantes & 2009 & 2 & Animação e fantasia & Start Desenhos Animados & 20th Century Fox \\
\hline $12 / 7$ & Tito e os pássaros & 2018 & 1 & Ação, infantil, drama, animação & Bits Produções & Elo Company \\
\hline $2 / 8$ & O menino da porteira & 2009 & 1 & Drama & Muraci Du Val & Columbia Pictures \\
\hline $9 / 8$ & O Grilo Feliz e os Insetos Gigantes & 2009 & 1 & Animação e fantasia & Start Desenhos Animados & 20th Century Fox \\
\hline $16 / 8$ & 31 minutos, o filme & 2012 & 1 & Comédia, infantil e aventura & Total Entertainment/User T38 & H20 Films \\
\hline $23 / 8$ & O diário de Tati & 2012 & 1 & Comédia e infantil & Globo Filmes & Vinny Filmes \\
\hline & Beth e Betinha & 2019 & & Documentário & - & - \\
\hline $26 / 8$ & A dama do rasqueado & 2017 & 2 & Documentário & - & - \\
\hline $30 / 8$ & High school musical & 2006 & 1 & Musical & First Street Films/Salty Productions & Disney-ABC Domestic Television \\
\hline $6 / 9$ & A raposa má & 2016 & 1 & $\begin{array}{l}\text { Comédia, infantil, aventura, } \\
\text { animação, fantasia }\end{array}$ & Folivari & Bonfim \\
\hline $13 / 9$ & Eu e meu guarda-chuvas & 2010 & 1 & Fantasia, aventura & Conspiração Filmes & 20th Century Fox \\
\hline $20 / 9$ & Billi Pig & 2012 & 1 & Comédia e ação & Globo Filmes & Imagem Filmes \\
\hline $27 / 9$ & Arte Deac & & & Infantil & - & - \\
\hline $4 / 10$ & O diário de Tati & 2012 & 1 & Comédia & Globo Filmes & Vinny Filmes \\
\hline $11 / 10$ & As Invensões de Akins & 2018 & 1 & Ficção & Ulisver Silva & - \\
\hline $25 / 10$ & O Bem Amado & 2010 & 1 & Comédia dramática & Buena Vista Internacional & Natasha Filmes/Globo Filmes \\
\hline \multirow{3}{*}{$01 / 11$} & Princesa Pantaneira & 2012 & \multirow[b]{3}{*}{1} & Infantil & - & - \\
\hline & Cordilheira de Amora II & 2015 & & Infantil & Tenda dos milagres & - \\
\hline & Ser Criança em Campo Grande & 2011 & & Infantil & - & - \\
\hline $08 / 11$ & Vídeo clipe Liga do Bem & 2020 & 1 & - & - & - \\
\hline $21 / 11$ & $\mathrm{O}$ ano que vem tem mais & & 1 & Documentário & - & - \\
\hline $22 / 11$ & Tropa de Elite 2 & 2010 & 1 & Drama, policial e ação & Zazen Produções & Zazen Produções \\
\hline \multirow[b]{2}{*}{$29 / 11$} & Nosso Lar & 2010 & \multirow[b]{2}{*}{1} & Drama & Cinemática Filmes & 20th Century Fox \\
\hline & Vídeo clipe Liga do Bem & 2020 & & - & - & - \\
\hline
\end{tabular}

Fonte: Autores. 
Foram disponibilizados recursos humanos para biossegurança, recepção, balizamento e organização dos carros, segurança. Ainda, estrutura de som, iluminação e projeção de vídeos foram inclusas.

Para desenvolvimento da ação, seguindo as recomendações municipal e da UFMS, as medidas de biossegurança foram elaboradas de modo a contemplar a ação. A equipe da vigilância sanitária do município, devidamente respaldadas com Equipamentos Proteção Individual (EPI), na recepção da infraestrutura, parte externa, aferiram a temperatura dos usuários no interior dos veículos, certificaram se estavam protegidos com máscaras e por fim, aplicaram álcool 70 nas mãos. Todos os servidores atuantes no local se mantiveram protegidos com máscaras, com higienização frequente das mãos com álcool 70 e distanciamento mínimo de 2 metros entre eles.

O projeto foi desenvolvido no período de junho a dezembro de 2020, aos sábados e domingos, com exibições de vinte e um filmes, em vinte e um dia. Todavia, conforme quadro 1, os filmes "O Grilo Feliz e os Insetos Gigantes", "Eu e meu guarda-chuvas", "O diário de Tati' e "Liga do Bem", foram exibidos em dois dias. No que tange a atualidade dos filmes, observa-se que a maioria deles foram lançados a mais de 10 anos.

A repetição de filmes e a predominância daqueles lançados a mais de 10 anos, decorreram das dificuldades em obter concessões para uso gratuito para projeção dos mesmos, haja vista que são produções protegidas pelos direitos autorais.

Conforme estabelece a Lei $\mathrm{n}^{\circ}$ 9.160, de 19 de fevereiro de 1998, que atualiza e consolida a legislação sobre direitos autorais, "a exibição audiovisual, cinematográfica ou por processo assemelhado, exige autorização prévia e expressa do autor a utilização da obra" (BRASIL, 1998, p. 5), vez que compete ao "titular dos direitos autorais colocar à disposição do público a obra, na forma, local e pelo tempo que desejar, a título oneroso ou gratuito (Brasil, 1998, p. 5), direitos estes morais e conexos, inclusive as cinematográficas, com 70 anos de proteção

Diante das dificuldades de cada possuidor dos direitos exercer a fiscalização do uso não autorizado de sua obra, autores representados por sociedades de gestão coletivas habilitadas junto ao Ministério da Cultura, dispõe de autonomia para cobrança do pagamento dos direitos autorais (Brasil, 2018), dentre elas, a InterArtis Brasil (IAB), Gestão de Direitos de Autores Roteiristas (GEDAR) e Diretores Brasileiros de Cinema e do Audiovisual (DBCA).

No caso de usuários primários, como cinemas públicos, os direitos por apresentação pública (obra é colocada ao alcance do público, por qualquer meio ou procedimento e que não consista na distribuição de exemplares), consiste em $1 \%$ do valor do ingresso ou da locação do filme. Ocasiões em que não é possível mensurar a utilização da obra pautada na renda bruta, é aplicada a cobrança da Unidade de Referência de Direito Autoral Audiovisual (URDAA) no valor correspondente a 5\% do salário mínimo (Diretores Brasileiros de Cinema e do Audiovisual, 2020).

Em que pese essenciais as normas que asseguram os direitos autorais e conexos aos autores de produções cinematográficas, o curto espaço de tempo e a quantidade de exibições planejadas para o projeto em relato, acabou limitando a utilização de obras cinematográficas disponibilizadas pelo SESC Mato Grosso do Sul, entidade de apoio da ação, restringindo a diversidade da programação possível de ser exibida, assim como uma programação mais variada, com filmes atuais.

As divulgações das sessões ocorreram pela Agência de Comunicação/UFMS via canais de comunicação em rádio (FM UFMS) e redes sociais (página oficial, instagram, facebook e youtube), Secretaria Municipal de Cultura e Turismo e veículos de comunicação de Campo Grande/MS.

O acesso foi gratuito, exclusivamente aqueles que se encontravam em veículos automotores (carros), com lotação máxima de 5 pessoas por veículo, em que os participantes permaneceram no seu interior até o final da ação.

Para que fosse mantido o controle do número máximo de uso do espaço, assim diminuir possíveis desconfortos por comparecimento ao local e não disponibilidade de vagas, os ingressos foram distribuídos três dias antes da realização, com $50 \%$ destinados a população interna a UFMS (que adotou sorteio entre os servidores e discentes interessados, cadastrados por 
intermédio de formulário online) e 50\% para SECTUR (que os distribuíram à população externa na Praça dos Imigrantes, por ordem de retirada).

Os resultados indicam que no período de 28 de junho a 29 de novembro de 2020, 2.701 pessoas, alocadas em 1.033 carros, se fizeram presentes no AutoCine UFMS para prestigiarem os vinte e um dia de exibição, que contou com a média de público de 128.61 pessoas por dia.

Figura 2. Frequência de pessoas e carros nas sessões do projeto "AutoCine UFMS: reviver histórias, ressignificar espaços e experiências de lazer em tempos de pandemia".

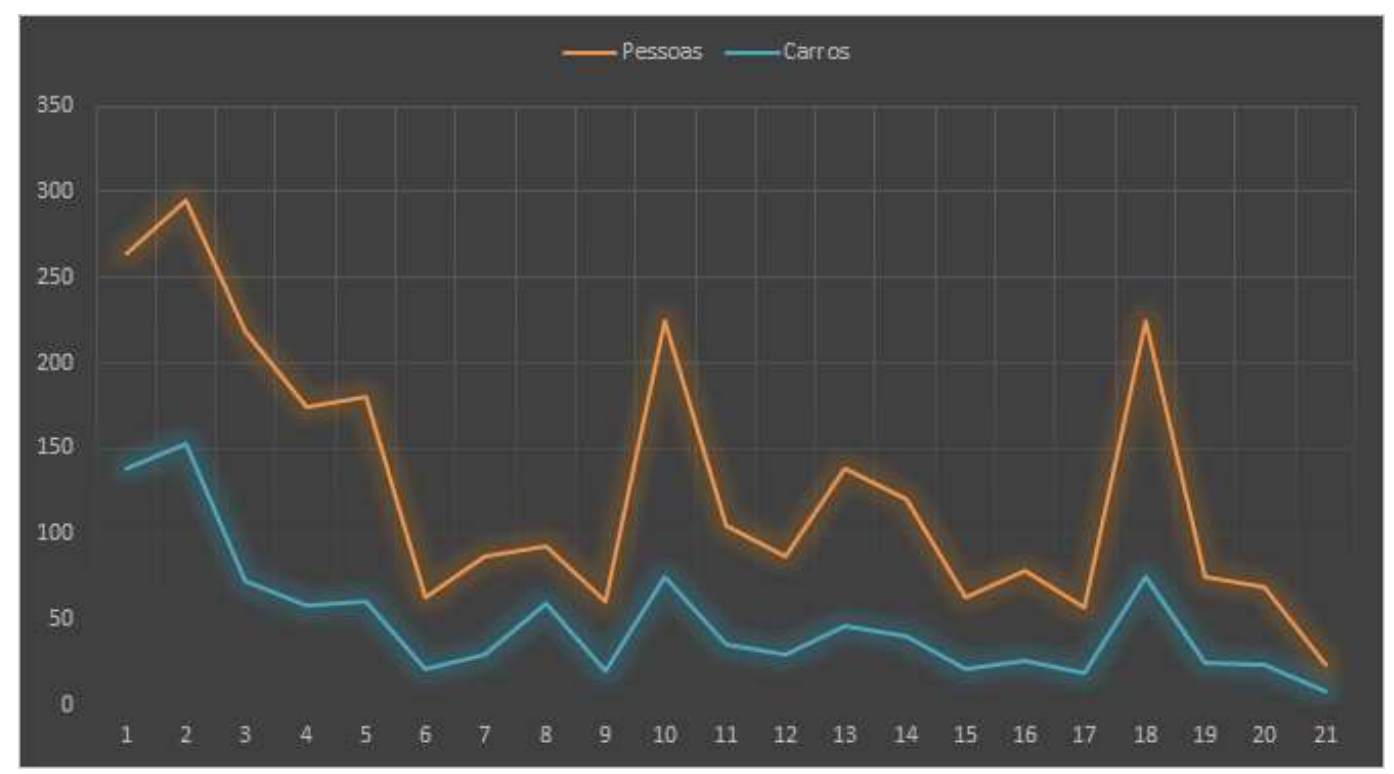

Fonte: Autores.

Observa-se que a participação do público ao longo dos vinte e um dia de exibições teve como auge o segundo, décimo e décimo oitavo dia, ocasiões em que foram projetados os filmes "O Grilo Feliz e os Insetos Gigantes", "High school musical" e "Liga do Bem". Os demais filmes apresentaram declínio de público, a maioria deles permeando a participação na faixa de 100 a 50 pessoas.

As dificuldades encontradas foram inerentes ao período de desenvolvimento da ação (pandemia), que exigiu redução das duas sessões projetadas para exibição de apenas uma, em decorrência da implantação de toque de recolher; cancelamentos de apresentações devido a medidas municipais que restringiam e flexibilizavam eventos artísticos em conformidade com o aumento dos casos de contágio do coronavirus.

No entanto, mesmo diante dos cancelamentos e limitação dos filmes projetados, a ação demonstrou ter corroborado com a criação de condições favoráveis ao lazer de interesse artístico vivenciados presencialmente pela população Campograndense, oportunidade essencial para o período de pandemia. Ademais, foi fundamental para reativação do Autocine, importante espaço de lazer que desde 1989 se encontrava desativado, sendo recomendado que sua apropriação com experiências artísticas de lazer, também ocorram em período pós-pandemia.

A relevância concebida ao projeto pode ser observada em entrevistas concedidas pelos participantes à jornais locais, que ressaltaram a importância do entretenimento durante a pandemia. 
Research, Society and Development, v. 10, n. 11, e300101119727, 2021

O primeiro depoimento indica a percepção sobre a relevância do projeto enquanto possibilidade de lazer no momento de pandemia, mas o atrelando ao entretenimento, ou seja, na ocupação do tempo disponível com experiências prazerosas e lúdicas.

[...] trouxe as filhas [...] e [...] para a sessão de estreia. Eles estavam no local pela primeira vez. "É algo totalmente diferente. Disseram-me que o filme é muito encantador. Esperamos voltar aqui, pois em momento de isolamento social, é essencial que atividades como essa aconteçam para proporcionar um entretenimento de forma ideal. Na entrada todas as medidas de segurança foram observadas. Nossas expectativas são grandes”, conta - Entrevistado 1 (Amim, 2020).

Outro participante, ressalta a importância das experiências artísticas no tempo de lazer, pontuando frequentemente irem a cinemas e teatros anteriormente a pandemia.

[...] veio com o marido e os filhos. "É difícil ficar sem fazer o que gostamos, pois íamos a cinema e teatro sempre, mas entendo que agora essa é uma boa opção para evitar maior transmissão do vírus”, conta. Ela estava ali pela primeira vez, porém o marido, [...], já conhecia o local - Entrevistado 2 (Amim, 2020).

O depoimento do entrevistado 2 indica que assume o lazer como valor em si mesmo, não lhe atribuindo função para além de satisfação de suas expectativas, o que podem contribuir para com o desenvolvimento social e pessoal, nas vivências de lazer.

Para aqueles que já haviam frequentado o espaço na década de 70, a reativação do AutoCine despertou certa nostalgia, os remetendo ao passado e experiências já vivenciadas no local.

“Estava com muitas saudades. O último filme que assisti aqui foi do Mazzaropi”, contou emocionado." A Casinha, do Mazaropi, em 1976", recorda [...], de 57 anos. Foi esse o filme que mais marcou o técnico em telecomunicações, assistido junto com o pai e os dois irmãos, aos 14 anos. As lembranças vieram à tona logo que ele cruzou os portões do Morenão, e pouco importava o filme a ser exibido - Entrevistado 3 (Brasil, 2020).

"Eu vim várias vezes, era tudo muita novidade, ter uma tela deste tamanho, onde você encostava o carro e pegava uma caixinha de som? Cada carro ficava ao lado de uma espécie de guarda-chuva pequeno, onde ficavam duas caixinhas de som para o veículo da direita e da esquerda, aí você pegava e colocava dentro do carro", explica Entrevistado 4 (Brasil, 2020).

"Quando eu cheguei, em 1984, eu morava bem ali, e ouvia todo o filme. É uma emoção você retornar, é uma memória afetiva que volta atrás, e é incrível hoje você poder estar dentro desse presente com uma coisa do passado. Quando ligou esse som, eu voltei 32 anos atrás" [...]. - Entrevistado 5 (Brasil, 2020).

Desde criança eu sempre imaginei o Autocine funcionando - Entrevistada 6 (Fernandes, P., 2020)

Nota-se nesses três depoimentos uma apropriação saudosista das experiências de lazer artístico no AutoCine, não ressaltando sua importância em relação ao momento pandêmico em si e o papel do projeto em criar alternativas de lazer voltadas ao desenvolvimento pessoal ou social, mas sim o resgate na memória dessa experiência de lazer realizada a mais de 30 anos. 
Research, Society and Development, v. 10, n. 11, e300101119727, 2021

(CC BY 4.0) | ISSN 2525-3409 | DOI: http://dx.doi.org/10.33448/rsd-v10i11.19727

No que tange ao lazer pautado no saudosismo, ele se dá pautado em certo romantismo, com ênfase em valores de sociedades anteriores, com nostalgia ao passado (Marcellino, 1987).

Outros três participantes ressaltaram a expectativa frente a existência do espaço e sua ociosidade que perdurou por trinta e um ano, em que ficou desativado e abandonado.

"É bem legal assistir e ver isso funcionando de volta. Eu já acompanhava a saga, porque trabalho aqui", diz o funcionário público [...]. - Entrevistado 7 (Brasil, 2020).

"Meu projeto foi a reforma do Autocine, quando fui fazer a pesquisa conversei com várias pessoas e nossa, como era bacana. Todo mundo dizia que era muito legal, e a gente sempre quis ver isso funcionando" - Entrevistado 8 (Brasil, 2020).

"[...], e em tempos tão difíceis esse projeto tem sido uma grande alternativa de acesso cultural seguro para todos. Foi uma experiência linda e emocionante poder viver essa 'viagem' pelos antigos cinemas de Campo Grande”, [...] Entrevistada 6 (Fernandes, P., 2020).

Observa-se nos depoimentos dos últimos entrevistados, uma percepção crítica a respeito do período que o espaço ficou inoperante e expectativa contínua da recuperação deste espaço de lazer, destacando a inoperância desse importante espaço de lazer ao longo desses anos que ficou fechado, algo que com sua reativação pode favorecer a democratização do acesso a experiências artísticas culturais no período de pandemia. Ainda, a última entrevista ressalta a relevância do projeto para fomentar experiência de lazer e acesso à cultura, por meio de condições de biossegurança adequadas.

\section{Conclusões}

Conclui-se que o projeto "AutoCine UFMS: reviver histórias, ressignificar espaços e experiências de lazer em tempos de pandemia", a partir das parcerias estabelecidas para revitalização e execução do projeto, possibilitou aos moradores de Campo Grande-MS experiências de lazer de interesse cultural artístico no período de pandemia, experiência de suma importância para o desenvolvimento pessoal e social da população.

Em que pese a relevância da ação, a participação oscilou ao longa da sua realização, com decréscimo do número de participantes, o que pode ser explicado pelos filmes que compuseram a programação, todos já lançados a mais de quatro anos, assim como pelo medo da pandemia e cancelamentos relacionados a mudanças no toque de recolher.

\section{Apoio}

O presente artigo foi realizado com apoio da Coordenação de Aperfeiçoamento de Pessoal de Nível Superior - Brasil (CAPES) - Código de Financiamento 001; Programa de Pós-graduação em Saúde e Desenvolvimento no Centro Oeste/Universidade Federal de Mato Grosso do Sul; Ministério de Educação por meio do fomento de bolsas no Programa de Educação Tutorial aos dois autores do artigo; Á Universidade Federal de Mato Grosso do Sul pelo financiamento do pagamento de taxa de publicação. 
Research, Society and Development, v. 10, n. 11, e300101119727, 2021

(CC BY 4.0) | ISSN 2525-3409 | DOI: http://dx.doi.org/10.33448/rsd-v10i11.19727

\section{Referências}

Amim, V. (2020). Autocine UFMS volta a exibir filmes depois de 30 anos. Agecom. Campo Grande. https://www.ufms.br/autocine-ufms-volta-a-exibir-filmesdepois-de-30-anos/

Bobbio, N. (1987). Estado, Governo e Sociedade: por uma teoria geral da política. Paz e terra.

Brasil, P. M. (2020). Curiosidade e nostalgia marcam a volta do Autocine na UFMS. Campo Grande News. Campo Grande. https://www.campograndenews.com.br/lado-b/diversao/curiosidade-e-nostalgia-marcam-a-volta-do-autocine-na-ufms

Brasil (1998). Lei n ${ }^{\circ} 9.610$, de 19 de fevereiro de 1998. Altera, atualiza e consolida a legislação sobre direitos autorais e dá outras providências. Diário Oficial da União, 225, p. 41. https://www.in.gov.br/web/guest/materia/-/asset_publisher/Kujrw0TZC2Mb/content/id/51525320/do1-2018-11-23-decreto-n-9-574-de22-de-novembro-de-2018-51525033

Brasil (2018). Decreto $\mathrm{n}^{\circ}$ 9.574, de 22 de novembro de 2018. Consolida atos normativos editados pelo Poder Executivo federal que dispõem sobre gestão coletiva de direitos autorais e fonogramas, de que trata a Lei $\mathrm{n}^{\circ}$ 9.610, de 19 de fevereiro de 1998 . Diário Oficial da União, 225 , p. 41. https://www.in.gov.br/web/guest/materia/-/asset_publisher/Kujrw0TZC2Mb/content/id/51525320/do1-2018-11-23-decreto-n-9-574-de-22-de-novembro-de$2018-51525033$

Cunha, C. A. et al. (2020). Informativo da Sociedade Brasileira de Infectologia: primeiro caso confirmado de doença pelo novo Coronavírus (COVID-19) no Brasil - 26/02/2020. São Paulo, Brasil: Sociedade Brasileira de Infectologia.

Demo, P. (2012). Metodologia científica em ciências sociais. 3. ed. São Paulo: Atlas.

Diretores Brasileiros de Cinema e do Audiovisual (2020). Regulamento da atividade de cobrança. Rio de Janeiro: DBCA. Retrieved from http://diretoresbrasil.org/a-dbca/

Dye, T. (2010). Mapeamento dos modelos de análise de políticas públicas. In Heidemann, F., \& Salm, J. F. (Org.). Políticas públicas e desenvolvimento: bases epistemológicas e modelos de análise (p. 99-129). Brasília: Editora Universidade de Brasília.

Dumazedier, J. (1979). Sociologia empírica do lazer. São Paulo: Perspectiva.

Fernandes, F. (2020). O que é um cinema drive-in. São Paulo. https://falauniversidades.com.br/o-que-e-um-cinema-drive-in-saiba-mais-sobre-sua-historia/

Fernandes, P. C. Comédia com Heloísa Périssé é a atração deste domingo na UFMS. Portal do Governo de Mato Grosso do Sul. http://www.ms.gov.br/comedia-com-heloisa-perisse-e-a-atracao-deste-domingo-na-ufms/

Governo do Rio Grande do Norte. Decreto n 29583 de 04 de abril de 2020. Consolida as medidas de saúde para o enfrentamento do novo coronavírus (COVID-19) no âmbito do Estado do Rio Grande do Norte e dá outras providências. Rio Grande do Sul. Governo Estadual, 2020. Diário Oficial do Estado do Rio Grande do Norte, 14637. http://diariooficial.rn.gov.br/dei/dorn3/docview.aspx?id_jor=00000001\&data=20200402\&id_doc=678994

Instituto Brasileiro de Geografia e Estatística. Sistema de informações e indicadores culturais: 2007-2018 (2019). Coordenação de População e Indicadores Sociais. Prefeitura Municipal do Rio de Janeiro: IBGE.

InLOCO (2020). Índice de isolamento social. Mapa brasileiro da COVID-19. Retrieved from https://mapabrasileirodacovid.inloco.com.br/pt/.

Liu, Y. et al. (2020). The reproductive number of COVID-19 is higher compared to SARS coronavirus. Journal of Travel Medicine, 27(2), 1-4. doi.org/10.1093/jtm/taaa021

Louro, G. L. (2000). O cinema como pedagogia. In Lopes, E. M. T., Filho, L. M. V., \& Veiga, C. 500 anos de Educação no Brasil. Belo Horizonte: Autêntica. p. 447-469.

Marcellino, N. C. (1987). Lazer e educação. 10ª ed. Campinas: Papirus.

Matos, L. S., Pinheiro, W. DA C., \& Bahia, M. C. (2020). Vivências do lazer para discentes do curso de educação física da universidade federal do Pará no contexto de pandemia da Covid-9. Licere, 23(3), 251-288. doi.org/10.35699/2447-6218.2020.25433

Mehta, P. et al. (2020). COVID-19: consider cytokine storm syndromes and immunosuppression. The Lancet, 395(28), 1033-1034. doi.org/10.1016/S0140$6736(20) 30628-0$

Ministério da Saúde (2020). Painel Coronavírus. Retrieved from https://covid.saude.gov.br/. Acesso em: 30/05/2020.

Paules, C., Marston, H. D., \& Fauci, A. S. (2020). Coronavirus Infections- More Than Just the Common Cold. JAMA, 323(8), 707-708. doi.org/10.1001/jama.2020.0757

Prefeitura Municipal do Rio de Janeiro. Decreto $\mathrm{n}^{\circ}$ 4728, de 21 de março de 2020. Determina a adoção de medidas adicionais, pelo Município, para enfrentamento da pandemia do novo Coronavírus - COVID - 19, e dá outras providências. Diário Oficial do Rio de Janeiro, 1589, p. 2. https://smaonline.rio.rj.gov.br/ConLegis/ato.asp?61095

Prefeitura Municipal de Campo Grande. Decreto $n^{\circ}$ 14.189, de 15 de março de 2020. Dispõe sobre as medidas para enfrentamento da emergência de saúde pública de importância internacional decorrente do Novo CoronavírusCOVID-19, e dá outras providências. Diário Oficial de Campo Grande, 5.856, p. 6. http://www.campogrande.ms.gov.br/sesau/downloads/decreto-n-14-189-de-15-de-marco-de-2020-covid-19-campo-grande-ms/

Rothana, H. A., \& Byrareddy, S. N. (2020). The epidemiology and pathogenesis of coronavirus disease (COVID-19) outbreak. Journal of Autoimmunity, 109, 102433. doi.org/10.1016/j.jaut.2020.102433 
Research, Society and Development, v. 10, n. 11, e300101119727, 2021

(CC BY 4.0) | ISSN 2525-3409 | DOI: http://dx.doi.org/10.33448/rsd-v10i11.19727

Silva, C. L., Bergamo, L. G., Antunes, D., \& Patreze, N. S. (2020). Os dias entre o teto e o chão da casa: lazer e práticas corporais no contexto brasileiro em tempos da COVID-19. Licere, 23(3), 57-92. doi.org/10.35699/2447-6218.2020.25111.

Silva, J. V. P. (2021). Impactos da covid-19 ao lazer de universitários. Holos, 37(4), 1-21. doi.org/10.15628/holos.2021.11146

Silva, J. V. P. da, \& Sampaio, T. M. V. (2011). Lazer e suas diversas faces. In Silva, J. V. P., \& Sampaio, T. M. V. Lazer e cidadania: horizontes de uma construção coletiva (p. 45-66). Taguatinga - DF: Universa, 2011.

Sousa, T. F., Fonseca, S. A., \& Barbosa, A. L. (2013). Perceived barriers by university students in relation the leisure-time physical activity. Rev. Bras. Cineantropom. Desempenho Hum., 15(2), 164-173. doi.org/10.5007/1980-0037.2013v15n2p164

Souza, C. (2006). Políticas públicas: uma revisão da literatura. Sociologias, 8(16), 20-45. doi.org/10.1590/S1517-45222006000200003

Tavares, G. H., Oliveira, D. P., Rodrigues, L. R., Mota, C. G., Sousa, T. F., \& Polo, M. C. E. (2020). Inatividade física no lazer durante a pandemia da COVID-19 em universitários de Minas Gerais. Rev Bras Ativ Fís Saúde, 25, e0178. doi.org/10.12820/rbafs.25e0178

Wit, E. et al. (2016). SARS and MERS: recent insights into emerging coronaviruses. Nat Rev Microbiol, 14(8), 523-534. doi.org/10.1038/nrmicro.2016.81 